Research Paper

\title{
Survival, Classifications, and Desmosomal Plaque Genes in Non-Small Cell Lung Cancer
}

\author{
Laura Boyero1, Abel Sánchez-Palencia², Ma Teresa Miranda-León³, Fernando Hernández-Escobar², Jose \\ Antonio Gómez-Capilla1, and $\mathrm{M}^{\mathrm{a}}$ Esther Fárez-Vidal1 ${ }^{\circledR}$ \\ 1. Department of Biochemistry and Molecular Biology, University of Granada School of Medicine, Granada, Spain. \\ 2. Department of Thoracic Surgery, Virgen de las Nieves University Hospital, Granada, Spain. \\ 3. Department of Statistics and Operative Research, University of Granada School of Medicine, Granada, Spain.
}

$\triangle$ Corresponding author: $\mathrm{M}^{\mathrm{a}}$ Esther Fárez-Vidal PhD. Biochemistry Department, University of Granada School of Medicine. $18012 \mathrm{Granada}$, Spain. Fax: +34958249015. e-mail: efarez@ugr.es. Tel: +34958246660

( ) Ivyspring International Publisher. This is an open-access article distributed under the terms of the Creative Commons License (http://creativecommons.org/ licenses/by-nc-nd/3.0/). Reproduction is permitted for personal, noncommercial use, provided that the article is in whole, unmodified, and properly cited.

Received: 2012.12.20; Accepted: 2013.04.15; Published: 2013.07.10

\begin{abstract}
Novel biomarkers are required to improve prognostic predictions obtained with lung cancer staging systems. This study of 62 surgically-treated Non-Small Cell Lung Cancer (NSCLC) patients had two objectives: i) to compare the predictive value of T-stage classifications between the $6^{\text {th }}$ and $7^{\text {th }}$ editions of the Tumor, Node, and Metastasis staging system (TNM); and ii) to examine the association of $\mathrm{Pkpl}$ and/or $\mathrm{Krtl} 5$ gene expression with survival and outcomes. Multivariate and Kaplan-Meier survival analyses were performed, examining the relationship of survival with T-stage, recurrence, and TNM-stage (by each TNM edition) and with the single/combined expression of $\mathrm{Pkpl}$ and/or $\mathrm{Krtl} 5$ genes. Five-year survival rates only significantly differed as a function of T-stage in patients without recurrence when estimated using the $6^{\text {th }}$ edition of the TNM classification and only in patients in pathologic TNM-stage IA using the $7^{\text {th }}$. Overall survival for patients with elevated expression of both genes was 13.5 months in those with adenocarcinoma and 34.6 months in those with squamous cell carcinoma. Overall survival was 30.4 months in patients with Pkpl gene upregulation and 30.9 months in those with $\mathrm{Krtl} 5$ gene upregulation. In conclusion, survival estimations as a function of T-staging differed between the $6^{\text {th }}$ and $7^{\text {th }}$ editions of TNM. Overall survival differed according to the expression of $\mathrm{PkPl}$ and/or $\mathrm{Krtl} 5$ genes, although this relationship did not reach statistical significance.
\end{abstract}

Key words: Survival, adenocarcinoma, squamous cell-carcinoma, non-small cell lung cancer, desmosomal plaque

\section{INTRODUCTION}

In males, the most frequent cancers are those of the lung, prostate, bronchus, and colorectum, which together accounted for $52 \%$ of all new cases worldwide in 2010. Lung cancer is the most commonly diagnosed cancer and leading cause of cancer death in men, accounting for $17 \%$ of total new cancer cases and $23 \%$ of total cancer deaths [1]. In females, lung cancer surpassed breast cancer as the leading cause of cancer death in 1987, becoming the fourth most frequently diagnosed cancer by 2008 and the second cause of cancer death. Lung cancer was estimated to account for $26 \%$ of all cancer deaths among females in 2010. A downward trend has been observed in the incidence of the four most prevalent cancers (breast, lung and bronchus, and colorectum) in both sexes with the exception of lung cancer in women, among whom rates are still increasing, although at a slower rate than in previous years. This trend is explained by the fact that cigarette smoking peaked around 20 years later in women than in men [1]. 
The substantial improvements in survival rates achieved by therapeutic advances in numerous cancer types since 1975 have not been observed in cancers of the lung or pancreas, and the mean 5-year survival rate is only $67 \%$ for patients with Tumor, Node and Metastasis (TNM) stage IA NSCLC and 57\% for TNM-stage IB NSCLC [1]. Although surgical resection is the leading curative treatment modality for early-TNM-stage NSCLC, outcomes have significantly varied after complete surgical resection in NSCLC patients with TNM-stage I [2].

In all lung cancers, staging is essential for the pathological determination of cell type and yields key information for the prognosis and therapeutic approach [3]. The staging system was modified in 2009 by dividing the different TNM stages into subgroups, based on observations of significant differences in survival rate between them [4]. The Union Internationale Contre le Cancer and American Joint Committee on Cancer recently established new criteria for the TNM staging of lung cancer, and the prognosis was redefined for various TNM groups. In the most recent $\left(7^{\text {th }}\right)$ edition of the TNM classification of the International Union Against Cancer (IUAC) staging system (2009), the International Association for the Study of Lung Cancer (IASLC) proposed the subdivision of T1 tumors into T1a $(\leq 2 \mathrm{~cm})$ and T1b $(2-3 \mathrm{~cm})$ groups [5], the subdivision of T2 tumors into T2a (3-5 $\mathrm{cm})$ and $\mathrm{T} 2 \mathrm{~b}(5-7 \mathrm{~cm})$ groups, and the reclassification of T2 tumors $>7 \mathrm{~cm}$ as T3, considering tumors with additional nodules in the same lobe as T3, tumors with ipsilateral intrapulmonary nodules in other lobes as T4; and tumors with pleural effusions (regardless of cytology) as M1 [3]. It was also recommended that pleural effusions in the absence of other metastatic sites be designated M1a, reserving the M1b stage for any other metastatic involvement [2].

Morphology-based lung cancer diagnosis can be inadequate because of the lack of typical morphologic features for early-TNM-stage NSCLC. Molecular genetic classification of cancer by expression analysis is frequently used in combination with clinical features to settle difficult diagnoses [6]. The molecular profiling of tumors and the identification of novel gene expression signatures by microarray platforms [7] can help to elucidate molecular events associated with lung cancer development and progression and can offer insights into human cancer expression patterns [8]. In a previous study, our group observed a high upregulation of plakophilin 1 (Pkp1) and keratin 15 (Krt15) genes in patients with lung squamous cell carcinoma (SCC) but not in those with adenocarcinoma (AC), indicating the potential value of these gene expressions for differentiating between these cancer types [9].

The desmosomal plaque protein Pkp1 has also been observed in cell nuclei, playing a nuclear signaling role [9]. It was found to be overexpressed in the most differentiated layers of stratified squamous epithelia such as skin, which likely reflects a difference between keratinized and non-keratinized tissues [10]. For their part, keratins are involved in the structural integrity of cells and tissue differentiation, and Krt15 is expressed in the basal keratinocytes of stratified epithelia and is used as a specific marker for stem cells of the hair-follicle bulge $[9,11,12]$.

With this background, the objectives of this study of surgically treated patients with different stages of NSCLC were i) to determine the relationship of T-stage, recurrence, and TNM-stage with their survival and compare the predictive value of T-stage classifications between the $6^{\text {th }}$ and $7^{\text {th }}$ editions of the TNM staging system for Lung and Pleural Tumors, and ii) to examine the association of Pkp1 and/or Krt15 gene expression with survival.

\section{PATIENTS AND METHODS}

\section{Tumor and non-tumor tissue samples, patho- logical evaluation and clinicopathological data.}

Samples of $\geq 100 \mathrm{mg}$ were taken from primary malignant lung tumors excised from 62 patients with NSCLC at Virgen de las Nieves Hospital (Granada, Spain) between 2004 and 2009. After thoracotomy and lung resection, tumor samples were processed following the procedure described elsewhere by Sanchez-Palencia et al. [9]. Informed consent was obtained from all patients for the study, which was approved by the Ethics Committee of our institution.

All patients were followed up at one month post-discharge and then every 3 months for one year, including plain chest $\mathrm{X}$-ray in posteroanterior view and blood analyses (full blood count and basic biochemistry). At one year, chest and upper abdominal CT studies and blood analyses were performed. Subsequently, patients were followed up every 6 months for the first 5 years and then every year for a minimum of 10 years post-surgery. Any patient missing a follow-up session was contacted by telephone to determine his/her health condition and, if deceased, the cause of death. We defined T-stage and TNM-stage variables according to both the $6^{\text {th }}$ and the $7^{\text {th }}$ editions of the TNM classification criteria.

When clinical, analytical, or radiographic findings led to suspicion of tumor recurrence, a tissue biopsy was conducted to confirm or rule out its presence. Survival time was calculated in months for each patient from the date of the surgical resection 
until death or, for survivors, until June 2010. Samples from patients who died in the postoperative period ( $<1$ month post-surgery) were excluded from the study.

\section{Adjuvant treatment after surgery}

Patients with pathological lymph node involvement (N1 or N2) received post-surgical adjuvant treatment with chemotherapy based on platinum doublets (cisplatin and vinorelbine) and regional radiotherapy.

\section{Tumor recurrence}

Local recurrence was defined by tumor relapse within the same lung or bronchial stump. Regional recurrence was defined by tumor relapse in mediastinal lymph nodes, despite their dissection during the primary surgery, or by metastases in contralateral mediastinal lymph nodes and/or supraclavicular region. Distant metastases were tumor lesions in an organ other than the lung under treatment or in remote lymph nodes.

\section{Expression levels of Pkp I and KrtI 5 genes.}

Expression data were obtained from microarray and quantitative real-time PCR (qPCR) analyses as described elsewhere [9]. Microarray analysis was carried out in a set of 40 samples (12 AC, 28 SCC), and qPCR was performed in an independent set of 21 samples (12 AC, 9 SCC). Non-tumor control samples $(n=38)$ were used to calculate fold-change $(F C)$ values.

Overexpression of Pkp1 and Krt15 genes was considered when the FC value was $\geq 2$-fold the mean FC of the control sample. Repression was considered when the FC value was $\leq 50 \%$ of the mean FC of the control sample.

\section{Statistical analysis}

The survival module of the SPSS v. 15.0 statistical program was used for the survival analysis, applying the Kaplan-Meier method to examine the relationship of patient survival with T-stage, recurrence, and stage and also with the single/combined overexpression of Pkp1 and Krt15 genes. T-stage classifications in the $6^{\text {th }}$ and $7^{\text {th }}$ editions of the TNM Classification and expression levels of Pkp1 and Krt15 were compared by means of the Breslow (generalized Wilcoxon), Tarone-Ware, and Log-Rank (Mantel-Cox) tests and by constructing survival curves as a function of T-stage, tumor recurrence, TNM-stage, and TNM edition. The Cox Proportional Hazards Regression Model (stepwise method) was applied to select the variables that significantly influenced the survival time. $P<0.05$ was considered significant.

\section{RESULTS}

Out of the original series of 73 patients operated for NSCLC, 9 died in the immediate postoperative period ( $<1$ month) and 2 were lost during the follow-up. Histological results showed that 37 of the final sample of 62 patients $(59.7 \%)$ had SCC and 25 $(40.3 \%)$ AC (Table 1). The mean age of the final sample was 68.34 years (range, 33-83 years); 6 were female $(9.7 \%)$ and 56 male $(90.3 \%)$. According to the $7^{\text {th }}$ edition of TNM classification criteria, $14(22.6 \%)$ were in pathologic TNM-stage IA, 22 in TNM-stage IB $(35.5 \%), 10$ in TNM-stage IIA $(16.1 \%), 12$ in TNM-stage IIB (19.4\%), and 4 in TNM-stage IIIA $(6.4 \%)$. According to the $6^{\text {th }}$ edition, 51 were in pathologic TNM-stage I (82.3\%), 5 in TNM-stage II (8.1\%), 5 in TNM-stage III (8.1\%), and 1 in TNM-stage IV $(1.5 \%)$. Among the final sample, the tumor diameter was $\leq 2 \mathrm{~cm}$ in 5 patients, $>2$ to $3 \mathrm{~cm}$ in $12,>3$ to $5 \mathrm{~cm}$ in $24,>5$ to $7 \mathrm{~cm}$ in 11 , and $>7 \mathrm{~cm}$ in 10 patients. All patients were followed up for 6 years or until their death, if sooner, finding a median overall survival (MOS) for the 62 patients of 55.2 months (up to June 2010).

The following variables were entered into the Cox regression model: tumor recurrence, $7^{\text {th }}$-edition TNM-stage, adjuvant treatment, cancer type (AC or SCC) and PKP1 and KRT15 gene expressions. The only variables selected for the final model were the $7^{\text {th }}$-edition TNM-stage in the first step and tumor recurrence in the second.

Kaplan-Meier survival analysis showed a significant result $(p=0.008)$ for the use of adjuvant therapy in patients with lymph node involvement, indicating that this variable influences patient survival in an individual manner, independent of the other variables. However, when all variables were entered into the Cox regression model, the adjuvant therapy variable was excluded and the $7^{\text {th }}$-edition TNM-stage was included, i.e., administration of adjuvant therapy did not influence patient survival after controlling for the other variables and might be associated with $7^{\text {th }}$-edition TNM-stage. After this observation of no significant difference in survival between patients with and without adjuvant treatment, the remaining statistical analyses were performed without distinguishing between them.

When $7^{\text {th }}$-edition TNM criteria were used to analyze survival, no significant differences were found as a function of T-stage $(p=0.385)$ or as a function of T-stage related to tumor recurrence $(p=0.508$ [with recurrence] and $p=0.931$ [without recurrence]) (Table $2)$, indicating that the survival was not influenced by tumor size, either alone or associated with tumor re- 


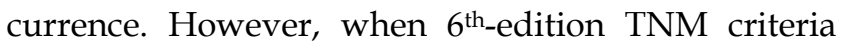
were used, survival rates significantly differed as a function of T-stage (T) $(p=0.006)$ and, when T-stage $(\mathrm{T})$ was analyzed in relation to tumor recurrence, significant differences were found among cases without tumor recurrence $(p=0.003)$ but not $(p=0.474)$ among those with recurrence.

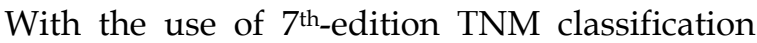
criteria, the survival significantly differed as a function of T-stage for patients in pathologic TNM-stage IA $(p=0.039)$ but not for patients in other TNM-stages $(p>0.05)$. With the use of $6^{\text {th }}$-edition criteria, no such significant differences were observed $(p>0.05)$.

Table I. Characteristics, stage (by $6^{\text {th }}$ and $7^{\text {th }}$ editions of the TNM Classification), and OS of patients.

\begin{tabular}{|c|c|c|c|}
\hline \multicolumn{2}{|l|}{ Characteristics } & Number & $\%$ \\
\hline \multicolumn{2}{|l|}{ Initial population } & 73 & 100.0 \\
\hline \multicolumn{2}{|l|}{ Lost to follow-up } & 2 & 2.7 \\
\hline \multicolumn{2}{|l|}{ Postoperative death } & 9 & 12.3 \\
\hline \multicolumn{2}{|l|}{ Patients studied } & 62 & 84.9 \\
\hline \multicolumn{4}{|l|}{ Gender } \\
\hline \multicolumn{2}{|l|}{ Male } & 56 & $90.3^{*}$ \\
\hline \multicolumn{2}{|l|}{ Female } & 6 & $9.7^{*}$ \\
\hline \multicolumn{4}{|l|}{ Histology } \\
\hline \multicolumn{2}{|l|}{ SCC } & 37 & $59.7^{*}$ \\
\hline \multicolumn{2}{|l|}{$\mathrm{AC}$} & 25 & $40.3^{*}$ \\
\hline \multicolumn{4}{|l|}{ Age (yrs) } \\
\hline \multicolumn{2}{|l|}{ Mean (range) } & 68.34 & \\
\hline \multicolumn{2}{|l|}{ Range } & $33-83$ & \\
\hline \multicolumn{4}{|l|}{ TNM Stage } \\
\hline \multirow[t]{5}{*}{$7^{\text {th }}$ edition } & IA & 14 & $22.6^{*}$ \\
\hline & IB & 22 & $35.5^{*}$ \\
\hline & IIA & 10 & $16.1^{*}$ \\
\hline & IIB & 12 & $19.4^{*}$ \\
\hline & IIIA & 4 & $6.4^{*}$ \\
\hline \multirow[t]{4}{*}{$6^{\text {th }}$ edition } & I & 51 & $82.3^{*}$ \\
\hline & II & 5 & $8.1^{*}$ \\
\hline & III & 5 & $8.1^{*}$ \\
\hline & IV & 1 & $1.5^{*}$ \\
\hline \multicolumn{4}{|l|}{ OS (months) } \\
\hline \multicolumn{2}{|l|}{ Median for all patients } & 55.2 & \\
\hline \multicolumn{2}{|l|}{ Median for SCC patients } & 33.8 & \\
\hline \multicolumn{2}{|l|}{ Median for AC patients } & 25.1 & \\
\hline
\end{tabular}

Table 2. Differences in survival as a function of tumor classification by TNM edition.

\begin{tabular}{|c|c|c|c|}
\hline $\begin{array}{l}\text { TNM classification } \\
\text { edition }\end{array}$ & \multicolumn{2}{|l|}{ Variable* } & $p$-value ${ }^{* *}$ \\
\hline \multirow[t]{9}{*}{$6^{\text {th }}$} & \multicolumn{2}{|l|}{$\mathrm{T}$} & 0.006 \\
\hline & \multicolumn{2}{|l|}{ TR } & 0.000 \\
\hline & \multicolumn{2}{|l|}{$S$} & 0.000 \\
\hline & \multirow[t]{2}{*}{ T\&TR } & WTR & 0.474 \\
\hline & & WOTR & 0.003 \\
\hline & \multirow[t]{4}{*}{ T\&S } & I & 0.550 \\
\hline & & II & 0.292 \\
\hline & & III & 0.100 \\
\hline & & IV & - \\
\hline \multirow[t]{10}{*}{$7^{\text {th }}$} & \multicolumn{2}{|l|}{$\mathrm{T}$} & 0.385 \\
\hline & \multicolumn{2}{|l|}{ TR } & 0.000 \\
\hline & \multicolumn{2}{|l|}{ S } & 0.000 \\
\hline & \multirow[t]{2}{*}{ T\&TR } & WTR & 0.508 \\
\hline & & WOTR & 0.931 \\
\hline & \multirow[t]{5}{*}{ T\&S } & IA & 0.039 \\
\hline & & IB & - \\
\hline & & IIA & 0.510 \\
\hline & & IIB & 0.557 \\
\hline & & IIIA & 0.218 \\
\hline
\end{tabular}

* $\mathrm{S}=\mathrm{TNM}$-stage $\mathrm{T}=\mathrm{T}$-stage $; \mathrm{TNM}=$ Tumor, Node and Metastasis classification; $\mathrm{TR}=$ tumor recurrence; $\mathrm{WOTR}=$ without tumor recurrence; WTR = with tumor recurrence.

${ }^{* *} p$-values were calculated using the Log-Rank test.

The survival rate significantly differed between patients with and without tumor recurrence using both the $7^{\text {th }}(p<0.001)$ and $6^{\text {th }}(p<0.001)$ editions, indicating a longer survival in the patients without tumor recurrence. Survival significantly differed as a function of TNM-stage as defined by either the $6^{\text {th }}$ or $7^{\text {th }}$ edition ( $p<0.001$ for both). The MOS was 33.8 months for the 37 patients with SCC and 25.1 months for the 25 patients with AC, but this difference was not significant (Kaplan-Meier, $p=0.162$ ); i.e., patient survival was not influenced by the type of cancer.

In the qPCR study, the expression level of Pkp1 gene could not be obtained in two patients and the expression level of Krt15 gene could not be obtained in another two patients. Out of the patients with microarray or qPCR results, Pkp1 was overexpressed in $43 / 59$ patients $(72.9 \%), \mathrm{Krt15}$ in $51 / 59(86.4 \%)$, and both genes in 39/58 (67.2\%).

Pkp1 gene was overexpressed in $25 \%$ of AC cases and $96 \%$ of SCC cases according to microarray analyses and in $50 \%$ of AC cases and $78 \%$ of SCC cases according to qPCR analyses.

Among the 43 patients with elevated Pkp1 gene expression, the mean OS was 16.3 months in the 10 AC cases and 34.6 months in the 33 SCC cases. Krt15 
gene was overexpressed in $58.3 \%(7 / 12)$ of $\mathrm{AC}$ cases and $100 \%(28 / 28)$ of SCC cases in microarray analyses, and in $66.7 \%(8 / 12)$ of AC cases and $88.9 \%(8 / 9)$ of SCC cases in qPCR analyses. Among the 51 patients with elevated Krt15 gene expression, the mean OS was 24.1 months in the $16 \mathrm{AC}$ cases and 34.1 months in the 36 SCC cases. Among the 39 patients with overexpression of both genes, the mean OS was 13.5 months in the $6 \mathrm{AC}$ cases (6/39) and 34.6 in the 33 SCC cases. However, no statistically significant relationship was found between the OS and Pkp1 or Krt15 expression ( $p=0.221$ and $p=0.610$, respectively) or as a function of carcinoma type (AC or SCC) $(p>0.05)$ (Table 3 ) or between the OS and the simultaneous expression of both genes $(p=0.888)$.

In the Cox regression analysis to determine the variables with a significant independent effect on patient survival, $7^{\text {th-edition }}$ TNM stage was included in a first step and tumor recurrence in a second. A significant difference was found between $7^{\text {th }}$-edition TNM-stages IIB and IA $(p=0.004)$ and a borderline significant difference between $7^{\text {th }}$-edition TNM-stages IB and IA ( $p=0.090)$. The likelihood of death was between 1.115-fold and 7.395-fold higher in patients with than without tumor recurrence. The model excluded $7^{\text {th }}$-edition T-stage, cancer type, and gene expressions of Pkp1 and Krt15 ( $p>0.05)$.

Application of Fisher's test revealed that Pkp1 and Krt15 gene expressions were independent of the tumor recurrence variable $(p=1.000$ for Pkp1 and $p=0.305$ for Krt15).

\section{DISCUSSION}

In this study of surgically treated NSLC patients, survival outcomes by TNM-stage varied according to the TNM edition used. When $6^{\text {th }}$-edition criteria were applied, the 5-year survival rate was $80.4 \%$ for TNM-stage I $(n=51), 60 \%$ for TNM-stage II $(n=5)$ and $20 \%$ for TNM-stage III $(n=5)$. However, when $7^{\text {th-edition }}$ criteria were considered, the rate was $85.7 \%$ for TNM-stage IA ( $\mathrm{n}=14), 81.8 \%$ for TNM-stage IB $(n=22), 70 \%$ for TNM-stage IIA $(n=10), 66.7 \%$ for TNM-stage IIB $(n=12)$ and $25 \%$ for TNM-stage IIIA $(n=4)$. Significant differences among stages were observed with both editions. In our study, 35/62 (56.5\%) of the patients had the same TNM stage by both $6^{\text {th }}$

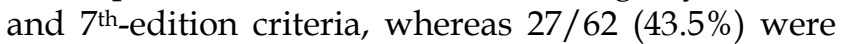
assigned a different TNM-stage according to the edition used.

Rena et al. [13] concluded that use of the $7^{\text {th }}$ edition of the lung cancer staging system improved the differentiation of operated NSCLC patients into prognostic sub-groups in comparison to the previous edition, reporting 5-year survival rates of $83 \%$ for TNM-stage IA, $77 \%$ for TNM-stage IB, $72 \%$ for TNM-stage IIA, $52 \%$ for TNM-stage IIB, and $29 \%$ for TNM-stage IIIA patients, (TNM-stages IIB vs. IIIA, $p=0.001$ ). Riquet et al. [14], using the $6^{\text {th }}$ edition, found that the 5-year survival rate of NSCLC patients decreased with increasing T-stage and staging from I to III, finding a rate of $65.5 \%$ for TNM-stage I, $54 \%$ for TNM-stage II, $24.3 \%$ for TNM-stage IIIA, and $50 \%$ for TNM-stage IIIB patients, with significant differences between TNM-stages I and IIIA and between TNM-stages II and IIIA.

Table 3. Analysis of expression levels of $\mathrm{Pkpl}$ and $\mathrm{Krtl} 5$ genes

\begin{tabular}{|c|c|c|c|c|c|c|c|c|c|c|}
\hline \multicolumn{2}{|c|}{ Expression level } & \multirow{2}{*}{$\begin{array}{l}\text { Data } \\
\text { Microarray }\end{array}$} & \multirow{2}{*}{$\begin{array}{l}\mathrm{n} \\
30\end{array}$} & \multirow{2}{*}{$\begin{array}{l}\text { Total } n^{*} \\
43\end{array}$} & \multirow{2}{*}{$\begin{array}{l}\% \\
72.9\end{array}$} & \multirow{2}{*}{$\begin{array}{l}\text { MOS } \\
\text { (months) }\end{array}$} & \multirow{2}{*}{$\begin{array}{l}\text { \% survivors } \\
74.4\end{array}$} & \multirow{2}{*}{$\begin{array}{l}p \text {-value }{ }^{* *} \\
0.221\end{array}$} & \multicolumn{2}{|c|}{$p$-value ${ }^{* * *}$} \\
\hline Pkp1 & Higher expression & & & & & & & & $\mathrm{AC}$ & 0.121 \\
\hline & & qPCR & 13 & & & & & & & \\
\hline & No change & Microarray & 10 & 12 & 20.3 & 36.5 & 75 & & & \\
\hline & & qPCR & 2 & & & & & & SCC & 0.564 \\
\hline & Lower expression & Microarray & 0 & 4 & 6.8 & 16.75 & 50 & & & \\
\hline & & qPCR & 4 & & & & & & & \\
\hline \multirow[t]{6}{*}{ Krt15 } & Higher expression & Microarray & 35 & 51 & 86.4 & 30.9 & 72.5 & 0.610 & $\mathrm{AC}$ & 0.512 \\
\hline & & qPCR & 16 & & & & & & & \\
\hline & No change & Microarray & 4 & 6 & 10.1 & 25.6 & 66.7 & & & \\
\hline & & qPCR & 2 & & & & & & SCC & - \\
\hline & Lower expression & Microarray & 1 & 2 & 3.4 & 37 & 100 & & & \\
\hline & & qPCR & 1 & & & & & & & \\
\hline
\end{tabular}

$\mathrm{n}=$ number of samples; $\%=\%$ of study sample of 59 patients; MOS = median overall survival; $\mathrm{AC}=$ adenocarcinoma; $\mathrm{SCC}=$ squamous cell carcinoma.

${ }^{* *} p$-values for the relationship between expression levels and survival, calculated using the Log-Rank test.

${ }^{* * *} p$-values for the relationship between expression levels as a function of carcinoma type and survival, calculated using the Log-Rank test. 
Table 4. Five-year survival rates using $6^{\text {th }}$ and $7^{\text {th }}$ TNM editions, showing median overall survival and percentage survival

\begin{tabular}{|c|c|c|c|c|c|c|}
\hline \multirow{2}{*}{$\frac{\text { TNM Stage }}{6^{\text {th }} \text { TNM edition }}$} & \multirow[b]{2}{*}{ I } & \multirow{2}{*}{$\begin{array}{l}\text { Number } \\
59\end{array}$} & \multirow{2}{*}{$\begin{array}{l}\text { Patients } \\
41 \text { survivors }\end{array}$} & \multirow{2}{*}{$\begin{array}{l}\text { MOS (months) } \\
35.5\end{array}$} & \multicolumn{2}{|c|}{$\%$ survivors } \\
\hline & & & & & 80.4 & \\
\hline & & & 10 non-survivors & 23.1 & & \\
\hline & & & 7 postop deaths & - & & \\
\hline & & & 1 lost to follow-up & - & & \\
\hline & II & 6 & 3 survivors & 25.7 & 60 & \\
\hline & & & 2 non-survivors & 14 & & \\
\hline & & & 1 postop deaths & - & & \\
\hline & III & 7 & 1 survivor & 16 & 20 & \\
\hline & & & 4 non-survivors & 21 & & \\
\hline & & & 1 postop death & - & & \\
\hline & & & 1 lost to follow-up & - & & \\
\hline & IV & 1 & 1 survivor & 30 & 100 & \\
\hline \multirow[t]{16}{*}{$7^{\text {th }}$ TNM edition } & IA & 14 & 12 survivors & 34 & 85.7 & 83.3 \\
\hline & & & 2 non-survivors & 27.5 & & \\
\hline & IB & 25 & 18 survivors & 34.2 & 81.8 & \\
\hline & & & 4 non-survivors & 19.8 & & \\
\hline & & & 2 postop deaths & - & & \\
\hline & & & 1 lost to follow-up & - & & \\
\hline & IIA & 14 & 7 survivors & 42.9 & 70 & 68.2 \\
\hline & & & 3 non-survivors & 16.3 & & \\
\hline & & & 4 postop deaths & - & & \\
\hline & IIB & 14 & 8 survivors & 30 & 66.7 & \\
\hline & & & 4 non-survivors & 24.3 & & \\
\hline & & & 2 postop deaths & - & & \\
\hline & IIIA & 6 & 1 survivors & 16 & 25 & \\
\hline & & & 3 non-survivors & 10.5 & & \\
\hline & & & 1 postop death & - & & \\
\hline & & & 1 lost to follow-up & - & & \\
\hline
\end{tabular}

MOS = median overall survival; Postop death $=$ death $<1$ month post-surgery; $\mathrm{TNM}=$ Tumor, Node and Metastasis classification.

Li et al. [2], using the $7^{\text {th }}$ edition, described 5-year OS rates of $75.5 \%, 74.6 \%, 60.9 \%, 55.6 \%$, and $46.2 \%$ for patients with tumor diameters of $\leq 2 \mathrm{~cm}(\mathrm{~T} 1 \mathrm{a}),>2-3 \mathrm{~cm}$ (T1b), >3-5 cm (T2a), >5-7 cm (T2b), and >7 cm (T3), respectively. They also reported that the 5-year OS after complete surgical resection significantly varied among patients with TNM-stage I NSCLC from 55\% to $77.6 \%$. When we used the staging subgroups recommended in the $7^{\text {th }}$ edition, we found 5-year survival rates of $83.3 \%$ for TNM-stage IA-IB $(n=30 / 36)$ and $68.2 \%$ for TNM-stage IIA-IIB $(n=15 / 22)$ (Table 4$)$.

Other factors may play important roles in the development of lung cancer and the survival of patients. Konaka et al. [15] reported a statistically significant relationship between tumor diameter and the depth of intrabronchial invasion, indicating that tumor invasion depth is an important variable in survival analysis [16].

In our study, although survival rates were higher for SCC than for AC patients, this difference was not significant $(p=0.162)$. Approximately $80 \%$ of patients with resected TNM-stage I (T1 N0 M0) SCC remain alive at five years after diagnosis versus around $70 \%$ of those with similarly staged ACs. Other authors found comparable differences in survival rate between TNM-stage II SCC and TNM-stage II AC [17]. However, Cooke et al. [18] observed a significantly reduced survival after lobectomy in SCC versus AC patients with TNM-stage I and II disease $(p<0.0001)$. Further comparative studies are required to clarify this issue.

Li et al. [2] concluded that the T-stage is a significant independent prognostic factor in TNM-stage I NSCLC. In the present analysis of survival as a function of T-stage, using Kaplan-Meier curves, significant differences were found among patients when the $6^{\text {th }}$ edition was used but not when the $7^{\text {th }}$ edition was applied. In the analysis of survival as a function of T-stage and TNM-stage, no statistically significant difference was found when the $6^{\text {th }}$ edition was used, 
but a significant difference was found for TNM-stage IA when the $7^{\text {th }}$ edition was employed. Furthermore, with the use of the $6^{\text {th }}$ but not the $7^{\text {th }}$ edition, significant differences in survival were observed for tumor recurrence and also for T-stage in cases without tumor recurrence.

In our previous study of gene signatures in primary AC and SCC [9], we determined differentially expressed gene sequences at different TNM-stages of the disease and identified sequences with biological significance for tumor progression. We then validated the expression level of 92 selected genes by qPCR and the Bonferroni test, identifying genes that were differentially expressed as a function of tumor type, TNM-stage, and differentiation grade, obtaining an acceptable concordance correlation coefficient [19] between our microarray and qPCR FC findings for each condition [9]. Thus, in all the validated genes, the change in expression was in the same direction (overexpression or repression) and there was no significant variation in FC values in the majority of comparisons. Among the patients evaluated with microarray analysis, survival was studied in 40 patients (12 AC [30\%], 28 SCC [79\%]) and among those undergoing qPCR analysis, survival was studied in 21 (12 AC [57.1\%], 9 SCC [42.9\%]). It should be noted that the $7^{\text {th }}$ edition of the TNM staging system had not been published at the time of our previous study, explaining our decision to perform the comparison between the two editions in the present investigation.

In the microarray analysis, patients with overexpression of Pkp1, a member of the armadillo protein family, had a mean OS of 30.4 months (16.3 months for AC cases vs. 34.6 months for SCC cases). In contrast, a previous study in patients with lung $\mathrm{AC}$ found that the overexpression of Pkp3, another armadillo family protein, was associated with poor survival and higher pathologic TNM-stage and TNM classification, suggesting that its expression plays a role in the development of lung cancer [20].

Patients with overexpression of $\mathrm{Krt15}$ had a mean OS of 30.9 months (24.1 months in AC cases, 34.1 months in SCC cases). Shi et al. [21] previously reported that the expression of $\mathrm{Krt15}$ and other keratins was elevated in lung SCC cells. Keratins may have a role as human biomarkers in carcinomas, improving the classification of lung cancer subtypes according to characteristic keratin profiles; however, further research is required on their involvement in lung SCC $[21,22]$.

The difference in gene expression results between analytical methods (e.g., 25\% [microarray] vs. $50 \%$ [qPCR] in AC cases) is explained by our criterion for considering Pkp1 and Krt15 genes to be overex- pressed (FC value $\geq 2$-fold mean FC of control sample). Hence, although the direction of the change was the same in all qPCR-validated samples, the gene was not considered overexpressed if the mean FC-fold value was $<2$.

The relatively small sample size is a study limitation, although the majority of our patients were in early TNM-stages of NSCLC, whose recruitment is more challenging given the usually late detection of this disease.

In this sample of surgically-treated NSCLC patients, survival outcomes related to tumor recurrence, tumor recurrence with T-stage, and TNM-stage with T-stage significantly differed according to the TNM classification edition used ( $6^{\text {th }}$ vs. $\left.7^{\text {th }}\right)$. Pkp1 gene overexpression was detected in almost three-quarters $(43 / 59)$ of studied patients, whose OS was 30.4 months. Krt15 gene overexpression was found in an even higher proportion (51/59), and the OS of these patients was 30.9 months. Further prospective studies are warranted to confirm these findings and establish the accuracy of $\mathrm{T}$ staging.

\section{ABBREVIATIONS}

AC: Adenocarcinoma; FC: Fold-Change; IASLC: International Association for the Study of Lung Cancer; IUAC: International Union Against Cancer; Krt15: Keratin 15; MOS: Median Overall Survival; NSCLC: Non-Small Cell Lung Cancer; OS: Overall Survival; Pkp1: Plakophilin 1; SCC: Squamous Cell Carcinoma; TNM: Tumor, Node, and Metastasis staging system.

\section{ACKNOWLEDGEMENTS}

This study was supported by the Carlos III Institute, Madrid [grant PI10.00198 to M.E. F-V].

\section{COMPETING INTERESTS}

The authors have declared that no competing interest exists.

\section{REFERENCES}

1. Jemal A, Siegel R, Xu J, Ward E. Cancer Statistics, 2010. CA Cancer J Clin. 2010; 60:277-300.

2. Li Z, Yu Y, Lu J, Luo Q, Wu C, Liao M, Zheng Y, Ai X, Gu L, Lu S. Analysis of the T Descriptors and Other Prognosis Factors in Pathologic Stage I Non-small Cell Lung Cancer in China. J Thorac Oncol. 2009; 4:702-09.

3. Shepherd FA, Crowley J, Van Houtte P, Postmus PE, Carney D, Chansky K, Shaikh Z, Goldstraw P; International Association for the Study of Lung Cancer International Staging Committee and Participating Institutions. The International Association for the Study of Lung Cancer Lung Cancer Staging Project: Proposals Regarding the Clinical Staging of Small Cell Lung Cancer in the Forthcoming (Seventh) Edition of the Tumor, Node, Metastasis Classification for Lung Cancer. J Thorac Oncol. 2007; 2:1067-77.

4. Deslauriers J, Grégoire J. Clinical and Surgical Staging of Non-Small Cell Lung Cancer. CHEST. 2000; 117:96S-103S.

5. Yoshida J, Nagai K, Asamura H, Goya T, Koshiishi Y, Sohara Y, Eguchi K, Mori M, Nakanishi Y, Tsuchiya R, Miyaoka E; Japanese Joint Com- 
mittee for Lung Cancer Registration. Visceral Pleura Invasion Impact on Non-small Cell Lung Cancer Patient Survival. Its Implications for the Forthcoming TNM Staging Based on a Large-Scale Nation-Wide Database. J Thorac Oncol. 2009; 4:959-63.

6. Välk K, Vooder T, Kolde R, Reintam MA, Petzold C, Vilo J, Metspalu A. Gene expression profiles of non-small cell lung cancer: survival prediction and new biomarkers. Oncology. 2010; 79:283-92.

7. Zhu CQ, Ding K, Strumpf D, Weir BA, Meyerson M, Pennell N, Thomas RK, Naoki K, Ladd-Acosta C, Liu N, Pintilie M, Der S, Seymour L, Jurisica I, Shepherd FA, Tsao MS. Prognostic and predictive gene signature for adjuvant chemotherapy in resected non-small-cell lung cancer. J Clin Oncol. 2010; 28:4417-24.

8. Kadara H, Fujimoto J, Men T, Ye X, Lotan D, Lee JS, Lotan R. A Gprc5a tumor suppressor loss of expression signature is conserved, prevalent, and associated with survival in human lung adenocarcinomas. Neoplasia. 2010; 12:499-505.

9. Sanchez-Palencia A, Gomez-Morales M, Gomez-Capilla JA, Pedraza V, Boyero L, Rosell R, Fárez-Vidal ME. Gene expression profiling reveals novel biomarkers in nonsmall cell lung cancer. Int J Cancer. 2010; 129(2):355-64.

10. Narayana N, Gist J, Smith T, Tylka D, Trogdon G, Wahl JK. Desmosomal component expression in normal, dysplastic, and oral squamous cell carcinoma. Dermatol Res Pract. 2010; 2010:649731.

11. Badock V, Steinhusen U, Bommert K, Wittmann-Liebold B, Otto A. Apoptosis-induced cleavage of keratin 15 and keratin 17 in a human breast epithelial cell line. Cell Death Differ. 2001; 8:308-15.

12. Yoshida S, Shimmura S, Kawakita T, Miyashita H, Den S, Shimazaki J, Tsubota K. Cytokeratin 15 can be used to identify the limbal phenotype in normal and diseased ocular surfaces. Invest Ophthalmol Vis Sci. 2006; 47:4780-6.

13. Rena O, Massera F, Robustellini M, Papalia E, Delfanti R, Lisi E, Pirondini E, Turello D, Casadio C. Use of the Proposals of the International Association for the Study of Lung Cancer in the Forthcoming Edition of Lung Cancer Staging System to Predict Long-Term Prognosis of Operated Patients. Cancer J. 2010; 16:176-81.

14. Riquet M, Manac'h D, Le Pimpec Barthes F, Dujon A, Debrosse D, Debesse $\mathrm{B}$. Prognostic value of $\mathrm{T}$ and $\mathrm{N}$ in non small cell lung cancer three centimeters or less in diameter. Eur J Cardiothorac Surg. 1997; 11:440-44.

15. Konaka C, Hirano T, Kato H, Furuse K, Takada M, Saito Y, Monden Y, Matsui E, Watanabe Y. Comparison of endoscopic features of early-stage squamous cell lung cancer and histological findings. Br J Cancer. 1999; 80:1435-39.

16. Chen C, Zheng H, Gao W, Zhou Y, Jiang S, Suen H. Prognosis and staging of superficial endobronchial lung cancer: the impact of invasion depth, tumor diameter, and coexistent pneumonitis or atelectasis. Chin Med J. 2010; 123: 1505-09.

17. Travis D, Brambilla E, Müller-Hermelink HK, Harris CC. WHO Classification; Tumors of the lung, pleura, thymus and heart. Albany, NY: WHO Publication Center. 2004.

18. Cooke DT, Nguyen DV, Yang Y, Chen SL, Yu C, Calhoun RF. Survival comparison of adenosquamous, squamous cell, and adenocarcinoma of the lung after lobectomy. Ann Thorac Surg. 2010; 90:943-8.

19. Carrasco JL, Jover L. Estimating the generalized concordance correlation coefficient through variance components. Biometrics. 2003; 59:849-58.

20. Furukawa C, Daigo Y, Ishikawa N, Kato T, Ito T, Tsuchiya E, Sone S, Nakamura Y. Plakophilin 3 oncogene as prognostic marker and therapeutic target for lung cancer. Cancer Res. 2005; 65:7102-10.

21. Shi I, Hashemi Sadraei N, Duan ZH, Shi T. Aberrant signaling pathways in squamous cell lung carcinoma. Cancer Inform. 2011; 10:273-85.

22. Wieskopf B, Demangeat C, Purohit A, Stenger R, Gries P, Kreisman H, Quoix E. Cyfra 21-1 as a biologic marker of non-small cell lung cancer. Evaluation of sensitivity, specificity, and prognostic role. CHEST. 1995; 108:163-9. 